\title{
Study Conduct Sub-Domain
}

National Cancer Institute

\section{Source}

National Cancer Institute. Study Conduct Sub-Domain. NCI Thesaurus. Code C93386.

The Study Conduct sub-domain is intended for those involved in the execution of a research study. The majority of business requirements have come from those involved in clinical trials. It focuses on the activities of conducting the study as well as the results from those activities. 